\title{
Outbreak of hand, foot and mouth disease caused by Coxsackie A16 virus in a childcare centre in Croatia, February to March 2011
}

S Ljubin-Sternak (sljsternak@hzjz.hr) ${ }^{1}$, V Slavic-Vrzic ${ }^{2}$, T Vilibić-Čavlek ${ }^{1}$, B Aleraj ${ }^{3}$, I Gjenero-Margan ${ }^{4}$

1. Department of Virology, Croatian National Institute of Public Health, and School of Medicine, University of Zagreb, Zagreb, Croatia

2. Department of Epidemiology, Zagreb County Institute of Public Health, Zagreb, Croatia

3. Department of Infectious Disease Epidemiology, Croatian National Institute of Public Health, Zagreb, Croatia

4. Department of Infectious Disease Epidemiology, Croatian National Institute of Public Health, Zagreb and School of Medicine, University of Rijeka, Croatia

Citation style for this article:

Ljubin-Sternak S, Slavic-Vrzic V, Vilibić-Čavlek T, Aleraj B, Gjenero-Margan I. Outbreak of hand, foot and mouth disease caused by Coxsackie A16 virus in a childcare centre in Croatia, February to March 2011.

Euro Surveill. 2011;16(21):pii=19875. Available online: http://www.eurosurveillance.org/ViewArticle.aspx?Articleld=19875

Article published on 26 May 2011

We describe an outbreak of hand, foot and mouth disease (HFMD) in a childcare centre in a district of Zagreb county, north-west Croatia. A total of eleven cases of HFMD occurred in the childcare centre and another nine were reported from nearby areas in the district. Coxsackie A16 virus was diagnosed in 13 clinical specimens obtained from 11 symptomatic and asymptomatic children. All cases resolved without complications.

\section{Outbreak description}

On 2 March, the Department of Epidemiology of Zagreb County Institute of Public Health was contacted by a health professional from a childcare centre in Bregana, Samobor district, reporting four children with vesicular stomatitis and rash (hand, foot and mouth disease, HFMD) in the weeks before. The centre cares for 160 children at two locations and comprises eight classes (seven classes in the main building complex and one class in a house nearby). Three cases were from one class at the first location and a fourth case was from the nearby house.
On the same day that the cases were reported, the epidemiologist found another two children with the same symptoms in the same class of the main building complex. The epidemiologist immediately reported the cases to the Reference Epidemiology Centre at the Croatian National Institute of Public Health. The day after, mouth swabs and stools were collected for viral culture from all children in the two affected classes. After active case finding (parent questionnaire, paediatrician reports), another five cases were found in other classes of the same childcare centre (11 cases in total). In this investigation, only symptomatic individuals were considered as cases, irrespective of laboratory-confirmation. All cases presented with a mild clinical picture of disease, with no complications, and only four of the 11 children attending the childcare centre stayed at home until they recovered. The affected classes were neither closed, nor were infected children separated. The management of the childcare centre was rather instructed to carry out an extensive cleaning and disinfection of all surfaces, toys, furnishings, toilets and other objects, while parents were given

\section{FIGURE}

Cases of hand, foot and mouth disease, by date of onset, Croatia, February-April 2011 (n=20)

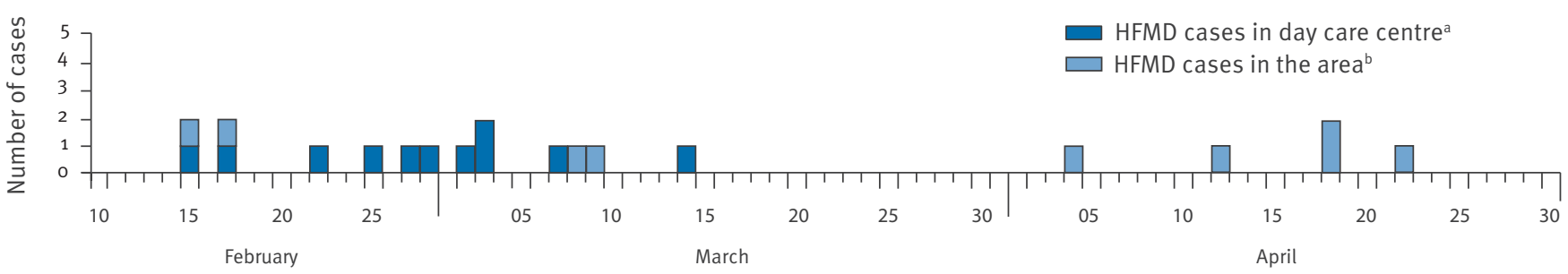

Date (2011)

HFMD: hand foot and mouth disease.

a Three of 11 cases were laboratory-confirmed for Coxsackie A16 virus infection.

${ }^{\mathrm{b}}$ Cases were clinically diagnosed. 
written materials on disease transmission and how to avoid it. No further cases occurred in the childcare centre after 14 March.

The epidemiologist also identified nine cases, outside the childcare centre, retrospectively by active case finding. These cases were also preschool children, aged one to four years, living in the Samobor district, which comprises about 43,000 inhabitants. The nine cases were all diagnosed by four primary care paediatricians taking care of most of the children in the area. After the outbreak in the childcare centre was recognised, the epidemiologist in charge of the investigation checked with them all the records and asked to report further cases. None of the cases outside the childcare centre were laboratory-investigated.

\section{Laboratory investigation}

A total of 57 clinical specimens (21 stool specimens and 36 throat swabs) were collected from the first six HFMD cases and a further 29 asymptomatic children aged from 1.5 to 5.5 years who attended the same classes as the first six cases at the childcare centre, as well as from their nurse. Specimens were forwarded to the World Health Organization (WHO) National Polio Laboratory at the Department of Virology, Croatian National Institute of Public Health for analysis. After pre-treatment, faecal suspensions and throat swabs were inoculated on green monkey kidney (GMK), human rhabdomyosarcoma $(\mathrm{RD}(\mathrm{A})$ ) and $\mathrm{L} 20 \mathrm{~B}$ (a recombinant mouse cell line expressing receptor for poliovirus) cell cultures, as a standard procedure for isolation of enteroviruses. Cell cultures were obtained from the WHO Labnet, National Public Health Institute, Helsinki, Finland. Viruses developed a cytopathic effect observed only on $\mathrm{RD}(\mathrm{A})$ cells, while there was no evidence of growth on GMK and L2OB cells. Identification of Coxsackie $\mathrm{A} 16$ (CA16) virus was done by microneutralisation assay using pooled equine hyperimmune sera prepared at the National Institute of Public Health and Environment (RIVM) Bilthoven, the Netherlands [1]. Laboratory results of CA16 virus isolation are presented in the Table.

\section{TABLE}

Coxsackie A16 virus isolation from symptomatic and asymptomatic children and their asymptomatic nurse Croatia, February-April 2011 ( $n=57$ specimens obtained from $\mathrm{n}=36$ individuals

\begin{tabular}{|l|c|c|}
\hline Clinical specimens & $\begin{array}{c}\text { Stools } \\
\text { positive/tested }\end{array}$ & $\begin{array}{c}\text { Throat swabs } \\
\text { positive/tested }\end{array}$ \\
\hline $\begin{array}{l}\text { Children with hand, } \\
\text { foot and mouth disease } \\
\text { symptoms }(n=6)\end{array}$ & $2 / 2$ & $1 / 6$ \\
\hline $\begin{array}{l}\text { Asymptomatic children } \\
\text { and nurse }(n=30)\end{array}$ & $8 / 19$ & $2 / 30$ \\
\hline Total $(n=36)$ & $10 / 21$ & $3 / 36$ \\
\hline
\end{tabular}

A total of 13 clinical specimens obtained from 11 children were positive. They comprised three of the six symptomatic cases and eight of the 29 tested asymptomatic contacts (Table). Asymptomatic individuals with a positive laboratory result were not considered as cases and are therefore not included in the Figure. In two children with a positive throat swab, the respective stool samples also tested positive, and in one child with a positive throat swab, a stool sample was not collected.

HFMD is a syndrome characterised by vesicular stomatitis and cutaneous lesions of the distal extremities and it is usually caused by CA16 or enterovirus 71 (E71). These viruses are genetically closely related and are both serotypes of the human enterovirus A (HEV-A) species, Picornaviridae family [2].

HFMD has a worldwide occurrence. Outbreaks occur frequently among groups of children in childcare centres and schools [3]. Transmission is by faecal-oral route and by exposure to throat discharges or fluid from blisters. In the absence of cutaneous lesions, oral lesions of HMFD may be mistaken for aphthous ulcers or herpes simplex gingivostomatitis [4]. Although described, neurologic complications of HFMD caused by $C_{A} 16$ are rare when compared to the disease caused by $E_{71}[5,6]$. Diagnosis of HFMD is usually based on the clinical picture alone. Laboratory diagnosis is usually performed by virus isolation of cell culture from throat swabs and stool specimens.

Enterovirus infections are notifiable diseases in Croatia. Usually, there are few reports of sporadic cases of HFMD each year, diagnosed based on the clinical picture alone. There are also several different serotypes of enteroviruses isolated in Croatia each year [7] but laboratory confirmed cases caused by $\mathrm{CA} 16$ virus have not been registered until now.

\section{Discussion}

$\mathrm{CA}_{16}$ and $\mathrm{E}_{71}$ are prevalent in many parts of the world, especially in south-east Asia $[5,6,8]$, but also in European countries $[9,10]$. In Croatia CA16 infections have not been documented until now, although these occur in neighbouring countries [9]. The traditional technique for detecting and characterising enteroviruses, also used in this laboratory, relies on viral isolation in cell culture followed by neutralisation using reference antisera. However, no single cell line exists that is capable of growing all human enteroviruses [2]. In 2004, RD(A) cells were introduced into the routine laboratory diagnostic algorithm for enterovirus culture together with previously used GMK and L2OB cells. This has resulted in the detection of HEV-A viruses including CA16 and E71, which grow poorly, if at all, in the other two cell lines used in our laboratory. Immediate collection of clinical specimens by the epidemiologist during the investigation of this outbreak also contributed to the successful isolation of CA16. 
$\mathrm{CA}_{16}$ and $\mathrm{E}_{71}$ are associated with sporadic cases and outbreaks of HFMD, and rare cases of acute neurological diseases. The HFMD outbreak reported here confirmed the previously observed characteristics of CA16 infection. An outbreak occurred in a childcare centre in children aged 1.5 to 5.5 years, who seem to be the most susceptible age group for CA16 infection. A seroprevalence study in Germany showed that two thirds of children aged 1 to 4 years do not posses neutralising antibodies to CA16 [10]. HFMD is a highly contagious disease, but the manifestation rate of infection is low. A large number of exposed children in this outbreak were infected as by laboratory confirmation (11/35). Most of the infected children were asymptomatic (8/11). The illness is usually mild without complications, as confirmed during this outbreak. The number of positive stool specimens versus throat swabs in symptomatic as well as asymptomatic children in this report confirmed that stool is the most appropriate clinical specimen for enteroviruses in which they survive for a long period.

In conclusion, a prompt reaction of the Epidemiology Service and the thorough investigation that followed, allowed the successful implementation of control measures which prevented further spreading of the HFMD outbreak in the childcare centre. CA16 appeared to have been circulating in the Samobor area from February, but as symptoms are mild or absent in most cases, many parents may not have sought medical help for their children.

\section{References}

1. World Health Organization (WHO). WHO Department of Immunization,Vaccines and Biologicals. Polio Laboratory Manual., 4th edition. WHO Document Production Services, Geneva, Switzerland, 2004; p.98-100.

2. Pallansch M, Roos R. Enteroviruses: polioviruses, coxsackieviruses, echoviruses, and newer enteroviruses. In: Knipe DM, Howley PM, editors. Fields virology. 5 th ed. Philadelphia: Lippincot W\&W-Wolters Kluwer, 2007. p. 839-93.

3. Frydenberg A, Starr M. Hand, foot and mouth disease. Aust Fam Physician. 2003;32(8):594-5.

4. Mehta KI, Mahajan VK. Hand foot and mouth disease. Indian Pediatr. 2010;47(4):345-6.

5. Goto K, Sanefuji M, Kusuhara K, Nishimura Y, Shimizu H, Kira R et al. Rhombencephalitis and coxsackievirus A16. Emerg Infect Dis. 2009;15(10):1689-91.

6. Chang LY, Lin TY, Huang YC, Tsao KC, Shih SR, Kuo ML et. al. Comparison of enterovirus 71 and coxsackie-virus A16 clinical illnesses during the Taiwan enterovirus epidemic, 1998. Pediatr Infect Dis J. 1999;18(12):1092-6.

7. Ljubin Sternak S, Vilibic-Cavlek T, Kaic B, Aleraj B, Soprek S, Sviben $M$ et al. Virological and epidemiological characteristics of non-polio infection in Croatia in ten year period (20002009). Acta med Croat 2011. Forthcoming. Croatian.

8. Wu PC, Huang LM, Kao CL, Fan TY, Cheng AL, Chang LY. An outbreak of coxsackievirus A16 infection: comparison with other enteroviruses in a preschool in Taipei. J Microbiol Immunol Infect. 2010;43(4):271-7.

9. Kapusinszky B, Szomor KN, Farkas A, Takács M, Berencsi G Detection of non-polio enteroviruses in Hungary 2000-2008 and molecular epidemiology of enterovirus 71 , coxsackievirus A16, and echovirus 30. Virus Genes. 2010;40(2):163-73.

10. Rabenau HF, Richter M, Doerr HW. Hand, foot and mouth disease: seroprevalence of Coxsackie A16 and Enterovirus 71 in Germany. Med Microbiol Immunol. 2010;199(1):45-51. 